\title{
Feeding the Vietnamese in the UK and the rationale behind their food habits
}

By Eleanor Carlson, M. Kipps and J. Thomson, Department of Hotel, Catering and Tourism Management, University of Surrey, Guildford, Surrey $\mathrm{GU}_{2}{ }_{5} \mathrm{XH}$

It is well known that natural resources and economics play a significant part in determining the kinds, the quality, and the quantity of the food we eat. This paper is primarily concerned with the way in which people use the food available to them; food consumption patterns rather than food preferences. Since 1979,15000 Vietnamese 'boat people' have been resettled in the United Kingdom. On arrival, the refugees were placed in thirty-seven reception centres scattered around Britain until homes could be found for them. The reception centres were run by three volunteer organizations: British Council for Aid to Refugees, Ockenden Venture and Save the Children.

The object of this study was to interview the refugees upon arrival to learn as much as possible about their traditional food habits before they could be overlaid by the food culture of the UK. In addition to collecting information on typical food habits, a study was also made of the kinds of catering systems used in the reception centres and to observe the reaction of the refugees to the different methods used. It was hoped that such a study would provide information on institutional catering for this cultural group as well as information for future reference in crisis feeding of other people.

It is estimated that $80 \%$ of the 'boat people' given asylum in the UK are ethnic Chinese, however since most have lived in Vietnam for three or more generations, they will be referred to as Vietnamese throughout this paper.

\section{Catering systems}

Most of the centres provided food as similar as possible to a typical Vietnamese diet to ease the period of adjustment and to meet both physiological and psychological needs. However the degree of refugee involvement in the planning, purchasing and preparation of meals varied considerably from one centre to another. The variety of catering systems employed ranged from one of self catering used by small centres where the Vietnamese were responsible for planning the meals, buying the food in local shops and preparing traditional dishes which were then eaten in family units, to communal catering, cafeteria style used by large centres where meals for 700 people were planned and purchased by a catering officer and prepared by a full time paid staff with little or no refugee involvement. The kind of catering system used was usually, but not always, dictated by the size of the institution, the facilities available and the amenities of the area in which the 
reception centre was located. For example, the accessibility of shops and markets for the refugees to buy their own food and the presence of a Chinese or Indian retail food shop in the area.

In some cases the food supplied reflected the food preferences of the host organization rather than the cultural food habits of the Vietnamese, e.g. cheese, margarine, jam, tinned beans. Some centres urgently promoted milk with no knowledge of milk usage or the extent of lactose intolerance among the Vietnamese.

The catering systems which were most successful from the standpoint of the Vietnamese, were those with the greatest degree of refugee participation; centres where they could purchase the food products, within a specified budget, for their own meals and centres where the cooking teams organized meals from a communal food supply. The self-purchasing units had the added benefit of introducing the Vietnamese to our system of weights, measures and money as well as the practical use of English.

A communal catering system with a paid staff may be the most effective way of ensuring that hundreds of people are fed regularly. However the argument put forward favouring the communal food system prepared by a permanent staff was that it relieved the refugee from all responsibility regarding his meals and he could therefore spend all his time going to classes to learn English. This was benevolently seen as a way of liberating the women from the kitchen and the responsibility of family meals and she could thereby keep pace with her husband and children in learning English. This policy, executed with good intent, excluded the family and particularly the women from any control over one of the most important functions in their lives and at the same time created other cultural problems which lie outside the ideas being discussed in this paper.

From these surveys, we began to piece together some information about basic consumption patterns and a system which governs basic food habits.

\section{Meal patterns}

The Vietnamese eating pattern is three meals a day. Breakfast can be as little as a cup of coffee or as much as a bowl of rice with meat and vegetables congee, or noodle soup with meat or fish and vegetables pho.

The mid-day and evening meals are of equal importance and have the same meal structure. Meal time is a family occasion and meals are delayed until as many family members as possible can be present.

The two major meals of the day consist of four basic dishes: rice, the basis of every meal, a thin soup made from bones, meat or fish stock and vegetables, a dish of meat or fish cooked with vegetables and a dish of vegetables. Condiments (fish, soya and chilli sauces, vinegar and sugar) are an important part of every meal. The number of side dishes accompanying the four basic dishes increases with income or on special occasions. Fresh fruit completes a meal with desserts being prepared only for special occasions. Except for special occasions when men drink beer or wine, beverages are generally not served with the meal and the thin soup functions 
as a thirst quencher. At the end of a meal men drink a cup of Chinese tea, while women, old people and children drink water.

Unlike the structure of the British meal described in detail by M. Nicod in 1974 (Douglas \& Gross, 1981) the Vietnamese do not differentiate between appropriate foods for breakfast, lunch and dinner, e.g. leftover food from the previous evening meal might be eaten for breakfast. Specific foods are not reserved for specific courses within a meal because all dishes are served and eaten simultaneously. Neither is there a sharp deliniation between when to eat a savoury and when to eat a sweet food; both appearing as equals within a meal, e.g. sweet sour sauces over meat, fish and vegetables and apples eaten with a sprinkling of salt. However the system of balancing foods within a meal is taken up later in the paper along with the subject of the rationale behind the structure of the diet.

Another important factor in Vietnamese consumption patterns is the way in which food is served. The practice in Western culture of heaping a variety of foods onto one plate at one time, blending flavours and juices is unacceptable to the Vietnamese. Each bite is collected separately from the communal serving dishes with the diners chopsticks, carried back to his rice bowl and then to his mouth. Rice is the primary food to be eaten on its own or to be flavoured with meat, fish, vegetables or condiments. A great deal of time is spent planning and preparing meals and presenting food in its most appetising form. Food is much more than a source of energy to the Vietnamese; it is also appreciated for its smell, taste and colour. Vegetables and meats are cut into bite sized pieces and the shape of the morsel must also please the eye.

Although the food in the reception centres was adequate, the way it was served often made it inedible to the refugees, especially in the centres using cafeteria catering. This is a factor which should be noted by hospitals, schools and other alternative domestic feeding situations involved in feeding the Vietnamese.

\section{Hospitality extended to guests}

The Vietnamese welcome guests at any meal of the day or on any day of the week, however days off work and feast days do take precedence. The reason given was 'we are more relaxed about time than people in the west'.

Hospitality in the Vietnamese home is shown by the quality and the quantity of food offered and a week's budget may be spent on one meal to entertain guests. It is not bad manners to leave uneaten food, in fact if all the food presented is eaten they feel they have not prepared enough. There has been a shortage of meat in Vietnam and a meal prepared for guests in Britain may be predominantly meat while the family surreptitiously eats a bowl of rice.

On arrival at a Vietnamese home, guests are always offered refreshment which might include a selection of beverages: strong black sweet coffee, Chinese tea without sugar or milk, or sweet wine. Again if the guest drains his cup or glass it will be refilled because an empty glass is an indication of thirst.

Guests may also be offered a cake or sweetmeat but the host seldom takes a beverage or a sweet for himself unless he is thirsty or hungry. Snacking between 
meals after the age of sixteen is not part of their basic food habits. Children however are allowed between meals snacks which might range from rice and bread to ice cream, coke and sweets.

\section{Some cultural food practices}

Because most homes in Vietnam lacked refrigeration, only fresh fruit, vegetables, fish and meats were used. An excess of food on one day or at one time of the year was pickled, dried or otherwise preserved for later use.

Most Vietnamese do not eat raw vegetables; this is probably due to the custom of using human waste as a fertilizer which helps to produce high yield crops but is also known to cause disease. The Vietnamese people have always made extensive use of wild plant and animal resources as well as home grown foods, and here in the UK those who have access to small areas of land are planting vegetable gardens. Therefore, as long as the Vietnamese continue to use natural waste as a fertilizer on their own plots, and it is understood that even those settled in the UK are still following this practice, they will continue to refrain from eating uncooked vegetables from other sources.

Milk and milk products have never been widely used in China and South-east Asia. In fact, the use of milk and milk products divides the people of Asia into two cultural groups: one depends on milk (Indians, Tibetans and many Central Asian nomads) and one rejects milk and milk products with loathing (Schafer, I977).

In ancient times milk was used as a sacrificial food in religious ceremonies (Simoon, 1970) and in recent times when fresh milk was available it was expensive and used only by the wealthy classes. When the rest of the population used milk it was in a tinned form (condensed and sweetened), but even this has been rationed in recent years and reserved for infants and old people.

Although the Vietnamese are aware of the nutritional value of milk, it has never been absorbed into their food culture. For a new food to be accepted by a culture group, it must fit into the existing patterns of food preparation and serving, however, the most likely reason for never adopting milk into their food habits may be a physiological intolerance to milk sugar (lactose) (Nong The Anh et al. 1977). Cases of lactose intolerance have appeared among the Vietnamese refugees but a detailed study is required to assess the extent of the problem and the age of onset.

In order to understand the specifics (the what, when and why) of individual food habits, it is necessary to look to the cultural origins of Vietnamese food habits.

The ethnic and cultural make-up of Vietnam is complex, with some sixty-three different ethnic groups (Lebar et al. 1964); however, much of its culture and many of its religions originated in China as a direct result of the rooo years of Chinese occupation (Vietnam Realities, 1969 ).

Unlike Islam, Hinduism or Judaism, the religions of Vietnam do not impose dietary laws upon the people, however, the basic Chinese concept of the universe and man's place in it, does introduce a system of control over diet. Laws which govern the universe also govern the individual and are inextricably mixed with diet and medicine. 
Vietnamese traditional medicine is composed of two elements: (1) Popular medicine thuoc nam or Southern medicine, which is entirely empirical, is based on recipes handed down from one generation to another (Le Tran Druc, 1977). (2) Thuoc bac, medicine of the scholars, came from China and is based on a system worked out according to the principles of ancient Chinese cosmogony (Le Tran Duc, 1977).

Thuoc nam uses many natural resources (leaves, flowers, fruit, bark, sap and roots of plants and trees as well as bone, antler, tendon, skin and hair of animals) and it is common for families to devote a patch of land for the cultivation of thirty-five species or more of plants for medicinal purposes (Nguyen Duc Minh, 1977). It is also claimed that Vietnams' use of phytotherapy, the use of vegetables in medicine, was an important factor in its ability to survive the devastation of modern warfare by providing 'on-the-spot' essential medical supplies (Hoang Bao Chau, 1977; McMichael, 1976). Some common plant foods used as diuretics, as laxatives or to treat diarrhoea, as antitoxic and antibacterial agents are onion, garlic, carrot, cinnamon and cloves (Nguyen Duc Minh, 1977).

Recipes in Vietnamese books and magazines, in addition to giving instructions for the preparation of a dish, give information on digestive and medicinal properties and comment on the vitamins present (Vietnam, I979).

The theoretical foundation of thuoc bac, which is referred to as traditional medicine, is based on a subtle logic in which two opposing but complementary forces - one being male yang or hot and the other being female yin or cold-are in dynamic equilibrium with the five universal elements (wood, fire, earth, metal and water) and their corresponding characteristics (Hoang Bao Chau, 1977). An harmonious balance of the five elements and yin and yang must be maintained to avoid discord. A person or a thing is neither totally yin or yang but shows varying degrees of the two forces until one or the other predominates (Connelly, 1979). For example a food is predominantly hot or cold, or equally balanced between the forces, in which case it is a neutral food such as rice or wheat noodles (Anderson \& Anderson, 1974).

A system of hot and cold foods exists in many parts of the world, however there appears to be no rule for the uninitiated to follow in classifying food into one category or the other. One refugee, who is a herbalist by profession, defined it as 'the energy which a food gives'. This was understood to mean the 'energy' imparted when all things are taken into consideration, i.e. the interrelation of other foods, the circumstances under which a food is eaten and the condition of the person eating it, not the calorific value of a food. Since each individual differs in his physiological requirements, it is reasonable to assume that the same food could appear hotter or colder to different people in different physical states.

Many of the Vietnamese interviewed found it difficult to classify isolated foods according to yin-yang or cold-hot properties, but they were quick to prescribe cold--hot foods for different physical conditions. For example, during pregnancy and puerperium foods have a universal designation. Cool foods (vegetables) are 
eaten during the last trimester, but avoided after childbirth. Hot foods (ginger and chillies) are heavily used during puerperium but not while pregnant. 'Green' (mung) beans are a cool food and when cooked with sugar, are eaten when a person is suffering from fever, constipation or dry sore throat; all hot conditions.

In Chinese philosophy, the universe is seen as an orderly system composed and governed by five elements. Each element relates to a season, a climate, a direction, a time of day, a colour and many more characteristics, such as five emotions (anger, joy, sympathy, grief, fear), five main internal organs (heart, liver, spleen, lungs, kidneys) plus five secondary viscera, five sensory areas (eyes, tongue, flesh, nose, ears) and five fluid secretions (sweat, urine, sputum, saliva, tears) (Crawford, I968; Connelly, i 979).

Each element also relates to a set of correspondence which apply to food: five flavours - tastes, five grains, five meats, five fruits, five vegetables. (Mote, 1977; Connelly, 1979). An equilibrium of all these qualities maintains health and a disequilibrium causes illness. Equilibrium is therefore regulated by the interaction of age, sex, temperament, season, food consumption and other activities (Leslie, 1976).

Accordingly to this philosophy, complex dietary laws do exist, and it is interesting to see how they translate into every day practice.

Since the diet is highly personalized; meals are discussed and planned with the requirements of individual family members in mind. There are the obvious physical needs which arise from different periods in the life cycle such as growing children, pregnant and lactating women and old age. In addition to these there are individual body states, e.g. colour of skin, itchy, tender, tingling skin, brightness or dullness of eyes, a feeling of hotness or coldness inside the body and many other states which could not be communicated because there were no English words to describe them. Such attention to the nuances of an individual physical state would be considered abnormal, neurotic behaviour by the standards of Western culture and people who do so are often classed as hypochondriacs.

The system of balancing the correspondences relating food to the five elements guarantees a variety of food in the diet. For example the five flavours (sour, bitter, sweet, pungent-spicy, salt) are basic to Vietnamese cooking. Lemons, lemon grass, tomatoes, vinegar, bitter melon, sugar, garlic, onions, ginger, chillies, soya sauce and fish sauce make up a short list of the condiments which are essential to traditional cooking and which are combined to flavour dishes or used as dipping sauces at the table. In addition to introducing variety, they also add valuable nutrients to the diet, e.g. chilli sauce is an excellent source of vitamin $A$.

Interviews with the Vietnamese refugees indicate that what they eat and why is regulated by principles similar to the law of the five elements and yin-yang. If they appear complex and ill defined to us, the system may not be completely clear to the people using it: "one should be aware that the principles of traditional scholarly medicine were based on the old Chinese cosmogony. Most of the time they are nebulous and hazy, even illogical in the light of modern science, and many a scientific worker has simply dismissed them. However, we cannot deny that they 
have some part in effective medical practice throughout the centuries' (Hoang Bao Chau, I977).

However Thoi Vy, a practitioner in Vietnam in the 3 rd century BC is reputed to have had a cure for scurvy (McMichael, 1976), and diet therapy in China throughout history is well documented (Anderson \& Anderson, 1974; Leslie, 1976; Chang, 1977; Mote, 1977; Schafer, 1977; Whang, 1981).

It is difficult to assess the extent of the Vietnamese refugees' nutritional knowledge, because their system of dietetics is alien to our way of thinking. The complex system of balancing the diet according to the principles of yin-yang and the five universal elements should not be over stressed, but it gives an indication of the system of examination and control applied to diet, regulated by the individual's needs, and passed from one generation to another around the family dining table. It is also an indication of the value the Vietnamese place on food in their hierarchy of man's needs and wants. These are concepts which we in the west find difficult to understand or accept.

\section{Nutritional content of a typical diet}

To obtain information on what constitutes a typical Vietnamese diet, a detailed study was made of the meals at one of the reception centres. Moyle Tower was a medium sized reception centre for eighty persons administered by the British Council for Aid to Refugees. Although the food at Moyle Tower was purchased by a catering officer, who was advised by a Vietnamese committee, meals were cooked by a rota of refugees who applied their own regional skills, tastes and food combinations to the dishes prepared. Meals were served in the traditional Vietnamese manner using communal serving plates, individual rice bowls and chopsticks and eaten in family units. In this way Moyle Tower was able to satisfy basic Vietnamese food habits using the British food supply.

The nutritional content of Moyle Tower meals was obtained by a computer analysis of the ingredients used. This analysis indicated that the Vietnamese diet was nutritionally adequate (Carlson et al. 1982 ). Probably an even more important indicator of the value of the Vietnamese diet structure is the source of energy in the diet (Table I).

Table I. Dietary energy derived from proteins, fats and carbohydrates as a percentage of total energy

\begin{tabular}{|c|c|c|c|c|c|}
\hline & $\begin{array}{l}\text { UK } \\
\text { I } 978^{*}\end{array}$ & $\begin{array}{l}\text { USA } \\
\text { ₹979! }\end{array}$ & $\begin{array}{c}\text { UK } \\
\text { Vietnamese } \\
\text { I } 980 t\end{array}$ & $\begin{array}{c}\text { USA } \\
\text { Vietnamese } \\
\text { 1 } 980^{+}\end{array}$ & $\begin{array}{l}\text { Peking-I } 979 \\
\text { Estimated from } \\
\text { hospital dietsll }\end{array}$ \\
\hline Protein & I $2 \cdot 9$ & I 2 & I 5 & 15 & $10-15$ \\
\hline Fat & $42 \cdot 0$ & 42 & 23 & 26 & $15-25$ \\
\hline Carbohydrate & $45^{-I}$ & $4^{6}$ & 62 & 59 & $60-75$ \\
\hline
\end{tabular}

*Household Food Consumption and Expenditure 1978-National Average.

†Casey ( 1980 ).

†T Calculated from Moyle Tower Survey.

$\|$ Yang ( $198 \mathrm{I})$. 


\section{Conclusions}

The traditional food habits of the Vietnamese are complex and, barring the differences in food products, cooking methods, meal structure and eating behaviour, their dietary system is also governed by a philosophy alien to western thinking. For the majority of British people, the dietary system followed in the west has failed to build the bridge linking the science of nutrition with the foods we eat. The 'boat people' are often looked upon as people originating from one of the under-developed countries of the world and therefore lack the technical knowledge of the developed countries. This cannot be said about their food knowledge.

Organisations and individuals extending aid and assistance to the 'boat people' often feel that the Vietnamese should adopt the food habits of their host country. The Moyle Tower study revealed that the traditional food habits of the Vietnamese are nutritionally viable in the UK and that the cost of their food is cheaper on average than the UK national diet. What is more important, the structure of the Vietnamese diet, high in carbohydrates and low in fats, closely approximates what is currently being recommended by nutritionists and health workers and we should therefore be copying the Vietnamese not the other way round.

The area where a conflict of food cultures is likely to be greatest is institutional catering such as in hospitals and schools. People in hospitals, already at a physiological and psychological disadvantage due to the insult which placed them in hospital in the first instance will be expected to improve and thrive on a diet culturally unrelated to Vietnamese traditional food therapy. However it is expected that school age children will experience the greatest cultural conflict. It is often said 'children adapt easily' but is this really desirable? Although a child would prefer an orange or an apple (maybe even one with salt) he will be served a sweet pudding and custard. By insisting on a child eating the traditional British school meal, we are forcing him to change his food habits. In a broader sense, the child will be forced to choose between what the school says is right and wants him to do and what his family says is correct, thereby increasing the conflict in cultures.

The evidence suggests that we should make every effort to learn more about the food habits of the non-indigenous cultural groups living in Britain. A greater understanding of how other cultures manage diet and control food habits will not only help us to understand the needs of other people living in the UK, but may also shed more light on nutrition education and diet in our own culture.

Eleanor Carlson currently holds the Carnation Research Fellowship at the University of Surrey, Guildford, Surrey.

\section{REFERENCES}

Anderson, E. N. \& Anderson, M. L. (1974). In Medicine in Chinese Cultures, p. 143. [Arthur Kleinman, editor] US Department of Health Education and Welfare, Public Health Service, National Institute of Health. 
Carlson, E., Kipps, M. \& Thomson, J. (1982). F. Hum. Nutr. Appl. Nutr. 36A, 107.

Casey, P. (1980). In Process of Transition, Vietnamese in Colorado [P. W. Van Arsdale and J. A. Pisarowicz, editors]. Texas: High Street Press.

Chang, K. C. (1977). In Food in Chinese Culture, Anthropological and Historical Perspectives [K. C. Chang, editor]. Newhaven \& London: Yale University Press.

Connelly, D. M. (1979). Traditional Acupuncture: The Law of the Five Elements. Maryland: The Centre of Traditional Acupuncture.

Crawford, A. C. (1 968). Customs and Culture of Vietnam. Japan: Charles E. Tuttle Company.

Douglas, M. \& Gross, J. (1981). Social Science Information, 20, I, p. I.

Hoang Bao Chau (1977). In Vietnamese Studies No. 50: Traditional Medicine, p. 20 and p. 27. Hanoi: Xunhaxaba.

Le Tran Duc (1977). In Vietnamese Studies No. 50: Traditional Medicine p. 130. Hanoi: Xunhaxaba.

Lebar, F., Hickey, G. C. \& Musgrave, J. (1964). In Ethnic Groups in South East Asia. New Haven: HRAF Press.

Leslie, C. (1976). In Asian Medical Systems, a Comparative Study. [Charles Leslie, editor]. Los Angeles, California: University of California Press.

McMichael, J. K. (1976). Health in the $3^{\text {rd }}$ World. Studies from Vietnam. Bertram Russell Peace Foundation, p. 188 and 204.

Mote, F. W. (1977). In Food in Chinese Culture, p. 227 [K. C. Chang, editor]. New Haven and London: Yale University Press.

Nguyen Duc Minh (1977). In Vietnamese Studies No. 50: Traditional Medicine, p. 51. Hanoi: Xunhaxaba.

Nong The Anh, Tran Kiem Thuc \& Walsh, J. D. (1977). Am. F. clin. Nut. 30, 468.

Schafer, E. H. (1977). In Food in Chinese Culture, Anthropological and Historical Perspectives, p. I05 [K. C. Chang, editor]. London and Newhaven: Yale University Press.

Simoon, F. J. (1970). Anthropos 65, 547.

Vietnam (1979). I 1, 251, 22.

Vietnamese Realities ( 1969 ). Saigon: Republic of Vietnam.

Whang, J. (1981). F. Am. Diet. Ass. 78, 55.

Yang, S. P. (1981). J. Am. Diet. Ass. 78, 57. 